\title{
Informing Instruction of Students with Autism in Public School Settings
}

\author{
Nai-Cheng Kuo (Corresponding author) \\ Department of Teacher Education, Augusta University \\ 2500 Walton Way, Augusta, Georgia 30904, USA \\ E-mail: nkuo@augusta.edu
}

Received: May 13, 2016 Accepted: June 8, 2016 Published: June 9, 2016

doi:10.5296/jei.v2i2.9456 URL: http://dx.doi.org/10.5296/jei.v2i2.9456

\begin{abstract}
The number of applied behavior analysis (ABA) classrooms for students with autism is increasing in K-12 public schools. To inform instruction of students with autism in public school settings, this study examined the relation between performance on mastery learning assessments and standardized achievement tests for students with autism spectrum disorders (ASD) in an applied behavior analysis (ABA) classroom. The measures included ABLLS-R, DIBELS-R, and DIBELS-M. Results of the study indicate that all students acquired new skills across domains and met their IEP goals measured by the mastery learning assessment, but they scored low on reading and math for their grade level according to standardized achievement tests. Suggestions for prompting good autism practice in public school settings are discussed.
\end{abstract}

Keywords: Autism, Applied Behavior Analysis (ABA), ABLLS-R, DIBELS, Cumulative measure

\section{Introduction}

Autism is considered the fastest growing developmental disability in the United States and elsewhere in the world. The prevalence of autism in the U.S. increased from 1 in 150 children in 2000 to 1 in 68 children in 2010 (CDC, 2016). The number of children with autism, 3 to 21 years old served under Individuals with Disabilities Education Act (IDEA), increased from approximately 94,000 in 2000 to 417,000 in 2011 (U.S. Department of Education, National Center for Education Statistics, 2016).

To improve the learning of students with autism and to promote these students' education in the least restrictive environment, applied behavior analysis (ABA) therapy grounded in scientific evidence has been highlighted since the 1980s (Lovaas, 1987). A variety of 
evidence-based practices carried out during ABA therapy includes differential reinforcement, discreet trial training, function behavior assessment, functional communication training, incidental teaching, peer-mediated instruction, picture exchange communication system, pivotal response training, redirection, self-management, social narratives, social skills training groups, stimulus control, structured work systems, verbal behavior intervention, video modeling, visual supports, and communication aid (Loiacono \& Allen, 2008; Odom, Boyd, Hall, \& Hume, 2010).

Although many private autism institutions have incorporated ABA therapy into their programs, ABA is also used in K-12 school settings to help students with autism achieve their individualized education program (IEP) goals. IEPs are a document prepared by a multidisciplinary team that specifies a student's annual learning goals and evaluation procedures. Typically, the IEP skill domains include: (1) cognitive skills, (2) social skills, (3) academic skills, (4) adaptive skills, and (5) motor skills. To determine if a student is demonstrating expected progress in essential skills and to inform future instructional decisions, different measures are utilized in school settings, such as mastery learning assessments and standardized achievement tests.

Mastery learning assessments are associated with Bloom's mastery learning. Bloom (1976) argues that all students can learn if systematical procedures of mastery learning are provided. In this mastery learning approach, teachers break down a skill domain into small skills and help students master these skills through high-quality instruction and effective learning engagement. Teachers constantly provide students with corrective feedback until they master the skills. The underlying assumption of mastery learning is that students' progression of learning skills increases the probability of their mastery of the whole skill domain (Bloom, 1976). The Assessment of Basic Language and Learning Skills - Revised (ABLLS-R), widely used in K-12 school settings, is considered a mastery learning assessment. For example, to develop and use motor skills, students with autism or other developmental disabilities need to master several skill tasks involving motor and muscular activities like dressing, grooming, and toileting.

Although the mastery learning assessments are promising and technically sound, it also receives a number of critiques. Fuchs, Fuchs, and Tindall (1986) note that the problems with using mastery learning in the reading classroom include lacking a connection between individual skills and actual reading behavior. They argue that many individual skills are arbitrarily and narrowly defined, which may not be related to or consistent with students' global reaching achievement (L. S. Fuchs, D. Fuchs, \& Tindall, 1986).

In opposition to mastery learning assessments, standardized achievement tests, such as Dynamic Indicators of Basic Early Literacy Skills (DIBELS), are timed tests and permit little flexibility for students with disabilities. Standardized achievement tests aim at knowing an individual's achievement in comparison with the achievement of his or her typical peers. Such tests are virtually identical to grade-level benchmark tests. Although standardized achievement tests have their strengths, cautions about misinterpretations of standardized achievement tests should not be overlooked. The threats to validity occur when students' 
deficits of social interaction, disruptive behavior, attention, as well as responding and motivational variables are often overlooked when interpreting the results of standardized achievement tests (L. K. Koegel, R. L. Koegel, \& Smith, 1997; Nation, Clarke, Wright, \& Williams, 2006).

Although ABA has contributed tremendously to education, particularly for students with autism (Dunlap, Kern, \& Worcester, 2001), the interaction between ABA intervention, students' IEP goals, and their performance on standardized achievement tests must be addressed to promote good practice for those who work with students with autism.

\section{Methods}

Given the lack of representation of racially diverse participants in special education and behavior-analytic research, this case study took place in a low income area with racially diverse participants. Five male kindergarten students at age five participated in this study. Among the five students, one of the students was Caucasian (Student N01) and the others were African Americans (Students K02, C05, K06, and Z08). In addition, Students C05 and Z08 had limited vocal language to communicate and thus a sign language and a picture exchange communication system (PECS) were utilized for them. The Battelle Developmental Inventory results showed that the five students had deficits in all developmental areas including cognitive, social, academic, adaptive, and motor skills. They met the state eligibility criteria for the significant development delay program and thus they received two hours of one-on-one ABA therapy in the morning and in afternoon with two different therapists on a daily basis. All therapists received 80 hours of ABA training directly from Board Certified Behavior Analysts (BCBAs) prior to their employment and were mandated to participate in professional development related to $\mathrm{ABA}$ throughout the year.

\subsection{Data Collection and Analysis Procedures}

There were three measures used in this ABA classroom to monitor these students' progress. The first measure, ABLLS-R, was developed by Partington (2016) as an assessment, curriculum guide, and skills tracking system for students with autism or other developmental disabilities. ABLLS-R is grounded in B. F. Skinner's behavioral analysis of language and has no diagnostic purposes for disability (Partington, 2016). It is a criterion-referenced assessment that can serve as a basis for identifying a student's current skills, guiding teachers to select new skills for the students, and ensuring that students maintain the skills and generalize the skills in different settings (Partington, 2016). Because ABLLS-R does not include specific steps necessary to provide treatments, the curriculum and activities were developed by the classroom teacher and implemented by therapists consistently. The 544 skills of ABLLS-R were grouped into the five skill domains to examine the students' progress toward their IEP goals (see Table 1). 
Table 1. Skill domains and ABLLS-R treatments

\begin{tabular}{|c|c|c|}
\hline IEP Goals & ABLLS-R Treatments & Number of Skills $(\mathrm{N}=544)$ \\
\hline Cognitive Domain & $\begin{array}{ll}> & \text { Cooperation and reinforce effectiveness (A1-19) } \\
> & \text { Visual performance (B1-27) } \\
> & \text { Receptive language (C1-57) } \\
> & \text { Motor imitation (D1-27) } \\
> & \text { Vocal imitation (E1-20) } \\
> & \text { Requests (F1-29) } \\
> & \text { Labeling (G1-47) } \\
> & \text { Intraverbals (H1-49) } \\
> & \text { Spontaneous vocalizations (I1-19) } \\
> & \text { Syntax and grammar (J1-20) }\end{array}$ & 314 \\
\hline Social Domain & $\begin{array}{ll}> & \text { Play and leisure (K1-15) } \\
> & \text { Social interaction (L1-34) } \\
> & \text { Group instruction (M1-12) } \\
> & \text { Classroom routines (N1-10) } \\
> & \text { Generalized responding (P1-6) }\end{array}$ & 77 \\
\hline Academic Domain & $\begin{array}{ll}> & \text { Reading }(\mathrm{Q} 1-17) \\
> & \text { Mathematics (R1-29) } \\
> & \text { Writing }(\mathrm{S} 1-10) \\
> & \text { Spelling }(\mathrm{T} 1-7)\end{array}$ & 63 \\
\hline Adaptive Domain & $\begin{array}{ll}> & \text { Dressing (U1-15) } \\
> & \text { Eating (V1-10) } \\
> & \text { Grooming (W1-7) } \\
> & \text { Toileting (X1-10) }\end{array}$ & 42 \\
\hline Motor Domain & $\begin{array}{ll}> & \text { Gross motor }(\mathrm{Y} 1-30) \\
> & \text { Fine motor }(\mathrm{Z} 1-28)\end{array}$ & 58 \\
\hline
\end{tabular}

Note. Adapted from Partington's (2016) ABLLS-R.

The second measure is DIBELS-R, which is "a set of procedures and measures for assessing the acquisition of early literacy skills from kindergarten through sixth grade" (DIBELS, 2016). DIBELS-R uses short and quick (i.e., one minute) assessments to measure their sound fluency (FSF), letter naming fluency (LNF), phoneme segmentation fluency (PSF), nonsense word fluency - correct letter sounds (NWF - CLS), and nonsense word fluency - whole words read (NWF - WWR) at the beginning of the year (BOY), in the middle of the year (MOY), and at the end of the year (EOY). The purpose of DIBELS is to identify in which 


\section{Macrothink

areas students are struggling with and to inform instructional decisions for preventing the occurrences of later reading difficulties (DIBELS, 2016). Table 2 shows the description of DIBELS-R.

Table 2. A description of DIBELS-R

\begin{tabular}{|l|l|}
\hline Reading Skills & Description \\
\hline $\begin{array}{l}\text { Fluency assessment to measure their } \\
\text { sound fluency (FSF) }\end{array}$ & FSF measures students' upper-and lower-case letter knowledge. \\
\hline Letter naming fluency (LNF) & LNF measures students' phonological awareness. \\
\hline Phoneme segmentation fluency (PSF) & $\begin{array}{l}\text { PSF measures students' ability to segment three- and } \\
\text { four-phoneme words into their individual phonemes fluently. }\end{array}$ \\
\hline $\begin{array}{l}\text { Nonsense word fluency - correct letter } \\
\text { sounds (NWF - CLS) }\end{array}$ & $\begin{array}{l}\text { CLS is the count of all correct letter sounds in the student } \\
\text { response. }\end{array}$ \\
\hline $\begin{array}{l}\text { Nonsense word fluency - whole words } \\
\text { read (NWF - WRR) }\end{array}$ & $\begin{array}{l}\text { WRC is the number of words that the child recoded (read as a } \\
\text { whole word) completely and correctly. }\end{array}$ \\
\hline
\end{tabular}

Source: DIBELS, 2016.

The third measure, DIBELS-M, assesses the basic math skills of students from kindergarten to Grade 3, including computation, concepts, counting, missing number, next number, number facts, number identification, and quantity discrimination (DIBELS ${ }^{\circ}$ Math, 2016). DIBELS-M is conducted at the beginning of the year, in the middle of the year, and at the end of the year to help teachers understand students' level of performance in math and to guide their instructional decisions. The description of DIBELS-M for kindergarten students is shown in Table 3. 
Table 3. A description of DIBELS-M

\begin{tabular}{|l|l|}
\hline Mathematics Skills & Description \\
\hline Counting & In counting, the student counts as high as he or she can in 60 seconds. \\
\hline Missing number & $\begin{array}{l}\text { Missing number is a measure that evaluates a student's recognition of } \\
\text { number patterns and familiarity with printed numbers. }\end{array}$ \\
\hline Number identification & $\begin{array}{l}\text { Number identification is a } 60 \text {-second measure that gauges a student's } \\
\text { ability to identify numerals. }\end{array}$ \\
\hline Quantity discrimination & $\begin{array}{l}\text { Quantity discrimination identifies a student's ability to comprehend the } \\
\text { quantitative value of whole numbers and operations using whole numbers, } \\
\text { fractions, and decimals. }\end{array}$ \\
\hline
\end{tabular}

Source: DIBELS ${ }^{\circledR}$ Math, 2016

The ABLLS-R skills taught in the ABA classroom of the present study were mainly through discrete trial training (DTT). When the student passed lower-level skills, higher-level skills would be introduced. To ensure that the intervention was provided based on protocols and the data was recorded properly, the classroom teacher supervised all the therapists on a daily basis. A cumulative measure was used in the present study for the author to examine the effects of ABLLS-R on five skill domains. If the student mastered the target skill, the researcher would put "yes" on that week when he mastered the skill. If the student did not master the target skill, the researcher would put "no" on that week to indicate his level of performance. The data collection was limited to recording a yes or a no due to the fact that mastery learning could only occur once per measurement period. Cumulative recording (Cooper, Heron, \& Heward, 2007) was used to accumulate the numbers of the students' mastered skills based on the domains (i.e., cognitive, social, academic, adaptive, and motor).

In addition to ABLLS-R, the DIBELS-R and DIBELS-M were conducted at the beginning, in the middle, and at the end of the academic year to all students in the school, including the students in the ABA classroom. Students' performance data on DIBELS-R and DIBELS-M were stored in the DIBELS online database.

\section{Results}

\subsection{ABLLS-R}

The ABLLS-R data indicates that after 26 weeks of ABA therapy, Student N01 made significant progress on the cognitive domain (from 0 to 33 skills), the social domain (from 3 to 12 skills), and the academic domain (from 0 to 12 skills). He also mastered some skills in the adaptive domain (from 1 to 4 skills) and the motor domain (from 0 to 1 skill) at the end of the academic year. Overall, the student mastered the skills identified in his annual IEP goals. His progress is shown in Figure 1. 


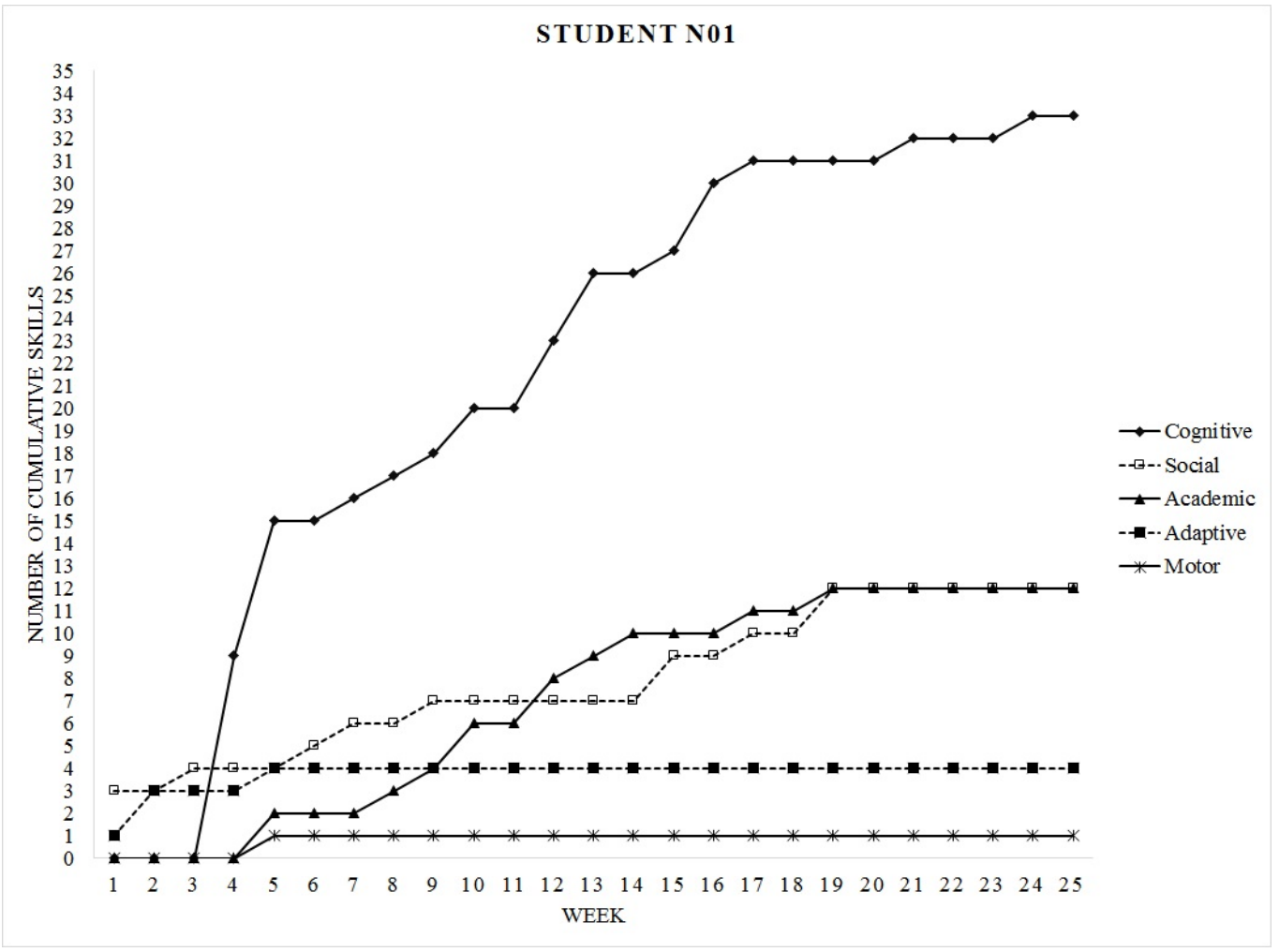

Figure 1. Student N01's performance on ABLLS-R

Student K02's ABLLS-R data shown in Figure 2 indicates that he made progress on the cognitive domain (from 1 to 26 skills), the academic domain (from 0 to 11 skills), and the social skills (from 2 to 10 skills) after 26 weeks of ABA therapy. He mastered some skills in the adaptive domain (from 1 to 4 skills) and the motor domain (from 0 to 1 skill) at the end of the academic year. The IEP team met at the end of the academic year and concluded that he met his annual IEP goals by mastering the ABLLS-R skills identified for him. 


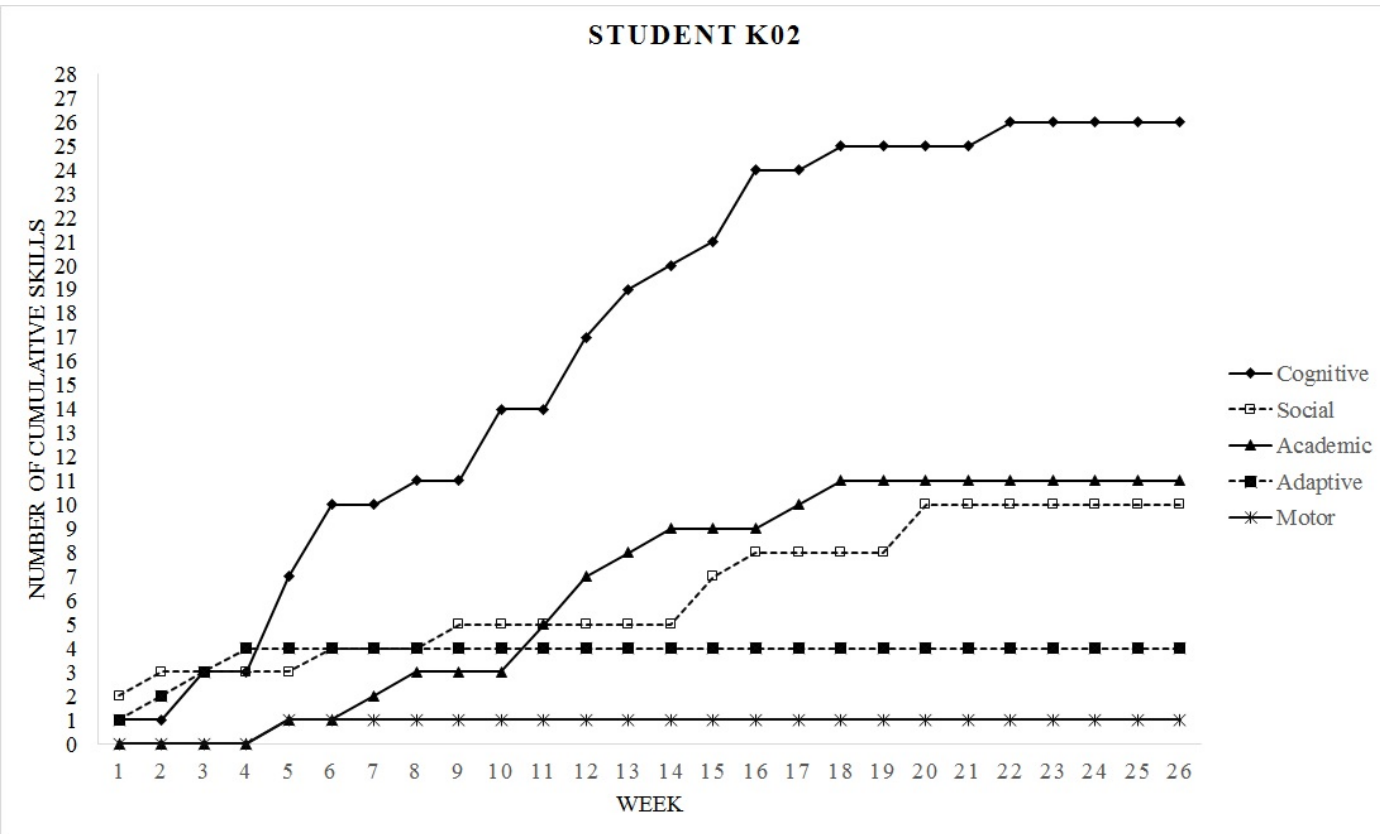

Figure 2. Student K02's performance on ABLLS-R

As shown in Figure 3, Student C05 made most of his progress on cognitive domain (from 2 to 16 skills). He made some progress on the social domain (from 0 to 6 skills), the academic domain (from 0 to 4 skills), the adaptive domain (from 9 to 4 skills), and the motor skills (from 0 to 3 skills). Student C05 also met his IEP goals.

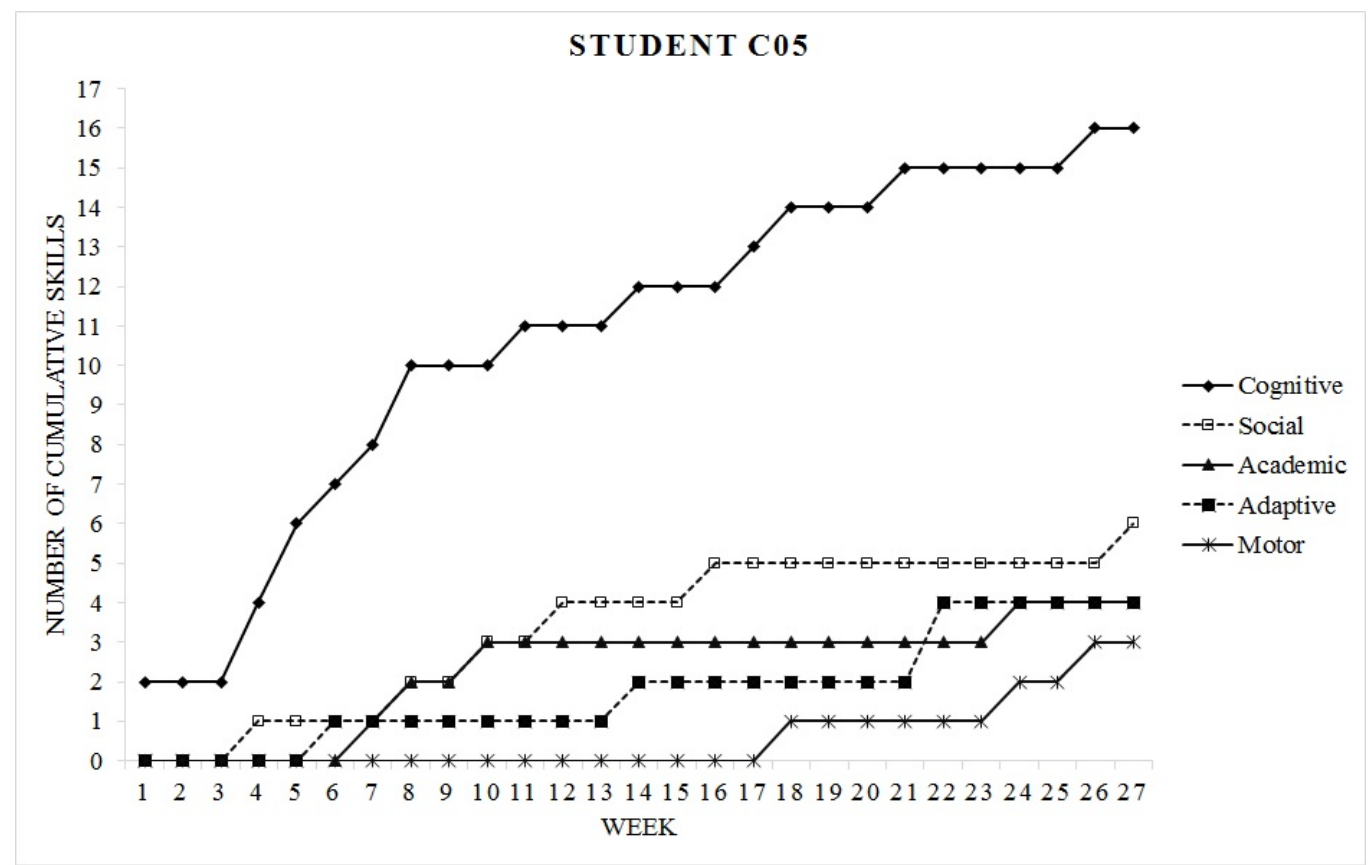

Figure 3. Student C05's performance on ABLLS-R 


\section{Macrothink}

After 27 weeks of ABA therapy, Figure 4 shows that Student K06 mastered twenty-two new skills in the cognitive domain, seven skills in the academic domain, six skills in the social domain, three skills in the adaptive domain, and one skill in the motor domain. He met his annual learning goals set by the IEP team.

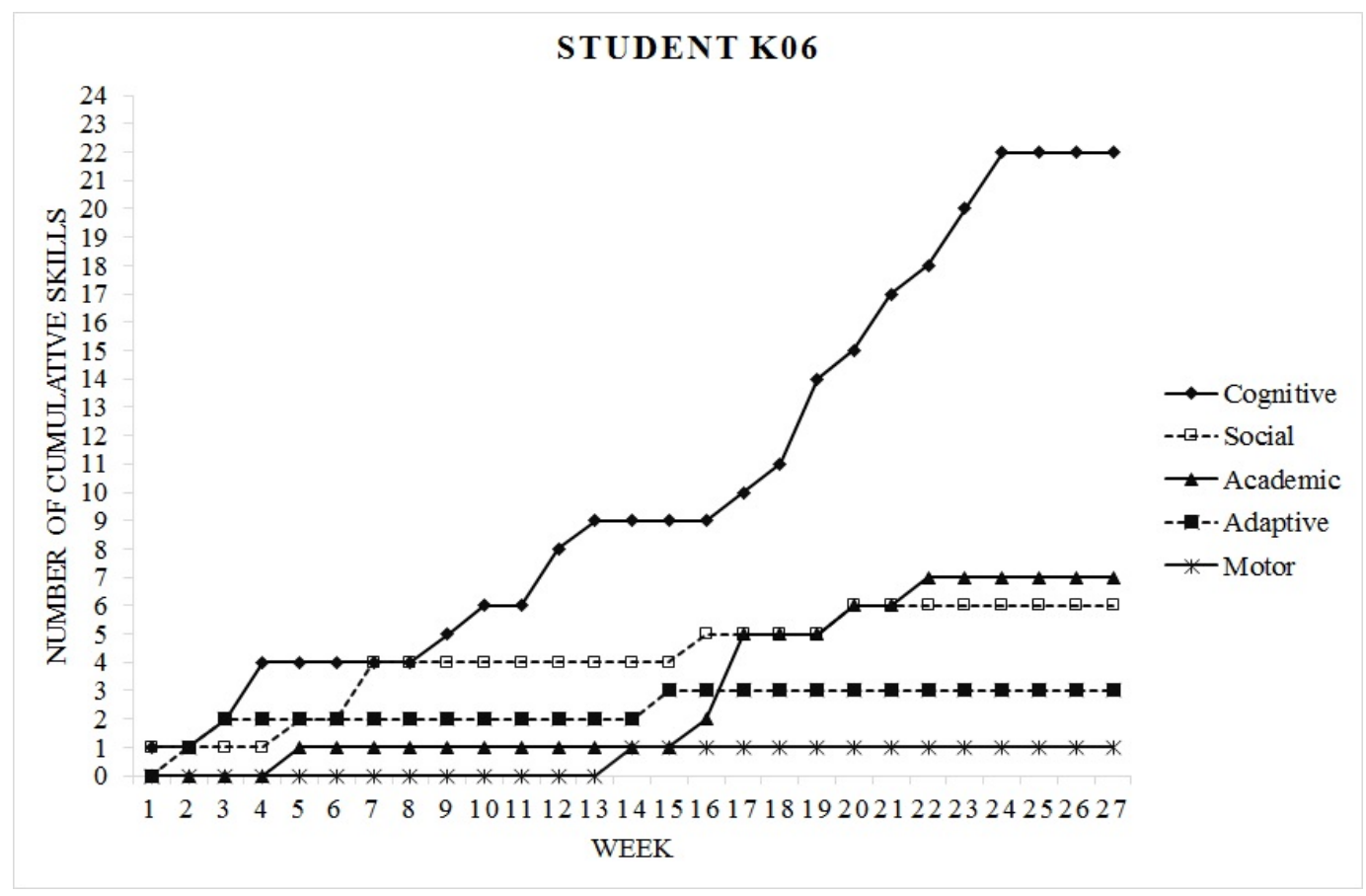

Figure 4. Student K06's performance on ABLLS-R

As for Student Z08, the ABLLS-R data indicates he mastered thirteen new skills in the cognitive domain, six skills in the social domain, two skills in both adaptive and motor domains, and one skill in the academic domain. He also met his IEP goals (see Figure 5). 


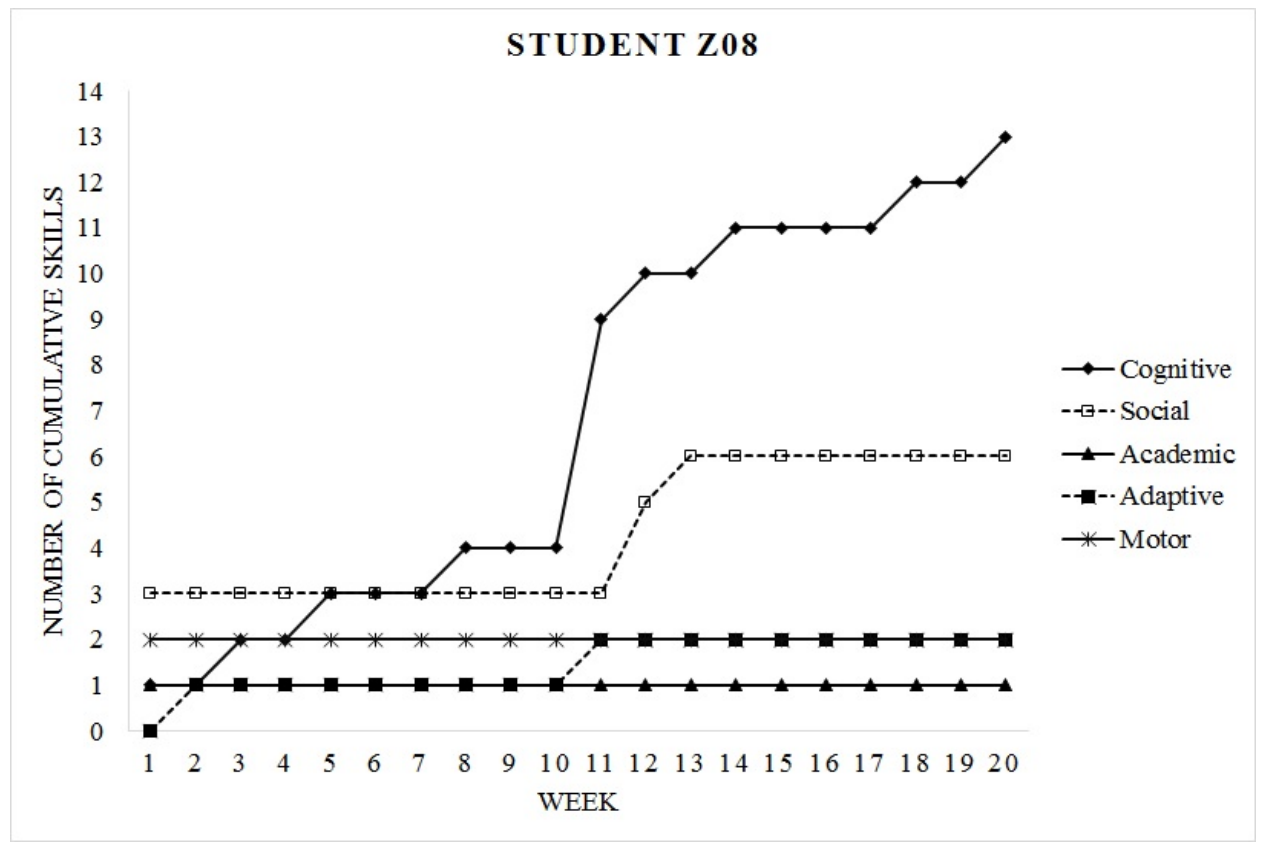

Figure 5. Student Z08's performance on ABLLS-R

In summary, all students made progress in the five skill domains of ABLLS-R, particularly in cognitive skills. At the end of the academic year, Student N01 mastered 62 skills, Student K02 mastered 52 skills, Student C05 mastered 33 skills, Student K06 mastered 39 skills, and Student Z08 mastered 24 skills. Table 4 displays an overview of the ABLLS-R skills that these students mastered.

Table 4. The number of students' accumulative skills across domains (end of the year)

\begin{tabular}{|l|l|l|l|l|l|l|}
\hline Student & Cognitive Skills & Social Skills & Academic Skills & Adaptive Skills & Motor Skills & Total \\
\hline N01 & 33 & 12 & 12 & 4 & 1 & 62 \\
\hline K02 & 26 & 10 & 11 & 4 & 1 & 52 \\
\hline C05 & 16 & 6 & 4 & 4 & 3 & 33 \\
\hline K06 & 22 & 6 & 7 & 3 & 1 & 39 \\
\hline Z08 & 13 & 6 & 1 & 2 & 2 & 24 \\
\hline
\end{tabular}

Table 5 and Table 6 present the students' performance data on the DIBELS-R and DIBELS-M. Some students made progress at the end of the year, while others did not. Overall, none of the students met their grade-level benchmarks in both DIBELS-R and DIBELS-M. 
Table 5. Students' performance on DIBELS-R

\begin{tabular}{|c|c|c|c|c|}
\hline & & BOY & MOY & EOY \\
\hline \multirow[t]{7}{*}{ N01 } & Overall & Yellow & Red & Red \\
\hline & FSF & 4 & 12 & - \\
\hline & LNF & 12 & 25 & 35 \\
\hline & PSF & - & 7 & 6 \\
\hline & NWF - CLS & - & 16 & 17 \\
\hline & NWF - WWR & - & 0 & 0 \\
\hline & & $(16)$ & $(60)$ & $(58)$ \\
\hline \multirow[t]{7}{*}{ K02 } & Overall & Yellow & Red & Red \\
\hline & FSF & 0 & 10 & - \\
\hline & LNF & 20 & 39 & 35 \\
\hline & PSF & - & 6 & 6 \\
\hline & NWF - CLS & - & 4 & 23 \\
\hline & NWF - WWR & - & 0 & 0 \\
\hline & & (20) & $(59)$ & $(64)$ \\
\hline \multirow[t]{7}{*}{$\mathrm{C} 05$} & Overall & Red & Red & Red \\
\hline & FSF & 0 & 0 & - \\
\hline & LNF & 4 & 11 & 13 \\
\hline & PSF & - & 0 & 0 \\
\hline & NWF - CLS & - & 11 & 11 \\
\hline & NWF - WWR & - & 1 & 3 \\
\hline & & (4) & $(23)$ & $(27)$ \\
\hline \multirow[t]{7}{*}{ K06 } & Overall & Green & Red & Yellow \\
\hline & FSF & 0 & 12 & - \\
\hline & LNF & 56 & 54 & 59 \\
\hline & PSF & - & 5 & 15 \\
\hline & NWF - CLS & - & 13 & 40 \\
\hline & NWF - WWR & - & 3 & 11 \\
\hline & & (56) & $(87)$ & $(125)$ \\
\hline \multirow[t]{2}{*}{ Z08 } & Overall & Red & Red & Red \\
\hline & FSF & 0 & 0 & - \\
\hline
\end{tabular}




\begin{tabular}{|l|l|l|l|l|}
\hline & LNF & 0 & 0 & 0 \\
\hline & PSF & - & 0 & 0 \\
\hline & NWF - CLS & - & 0 & 0 \\
\hline & NWF - WWR & - & 0 & 0 \\
\hline & & $(0)$ & $(0)$ & $(0)$ \\
\hline
\end{tabular}

Note. First sound fluency (FSF), letter naming fluency (LNF), phoneme segmentation fluency (PSF), nonsense word fluency - correct letter sounds (NWF - CLS), nonsense word fluency whole words read (NWF - WWR), beginning of the year (BOY), middle of the year (MOY), and end of the year (EOY). Red: The student needs the most intensive support because he/she is far below benchmark expectations. Yellow: The student needs some support because he/she is advancing toward but has not met benchmark expectations. Green: The student meets or exceeds benchmark expectations (DIBELS, 2016).

Table 6. Students' performance on DIBELS-M

\begin{tabular}{|c|c|c|c|c|}
\hline & & BOY & MOY & EOY \\
\hline \multirow[t]{6}{*}{ N01 } & Overall & Red & Red & Red \\
\hline & Counting & 11 & 41 & 49 \\
\hline & Missing number & 0 & 3 & 8 \\
\hline & Number identification & 4 & 10 & 12 \\
\hline & Quantity discrimination & 0 & 5 & 5 \\
\hline & & $(15)$ & (59) & (74) \\
\hline \multirow[t]{6}{*}{ K02 } & Overall & Red & Red & Red \\
\hline & Counting & 19 & 58 & 68 \\
\hline & Missing number & 1 & 0 & 5 \\
\hline & Number identification & 7 & 13 & 24 \\
\hline & Quantity discrimination & 8 & 8 & 11 \\
\hline & & $(35)$ & (79) & (108) \\
\hline \multirow[t]{6}{*}{$\mathrm{C} 05$} & Overall & Red & Red & Red \\
\hline & Counting & 13 & 2 & 0 \\
\hline & Missing number & 0 & 0 & 0 \\
\hline & Number identification & 15 & 11 & 7 \\
\hline & Quantity discrimination & 7 & 2 & 0 \\
\hline & & $(35)$ & (15) & (7) \\
\hline
\end{tabular}




\begin{tabular}{|l|l|l|l|l|}
\hline K06 & Overall & Yellow & Yellow & Yellow \\
\hline & Counting & 71 & 61 & 66 \\
\hline & Missing number & 0 & 15 & 21 \\
\hline & Number identification & 19 & 28 & 57 \\
\hline & Quantity discrimination & 7 & 9 & 7 \\
\hline Z08 & & $(97)$ & $(113)$ & $(151)$ \\
\hline & Overall & Red & Red & Red \\
\hline & Counting & 0 & 0 & 0 \\
\hline & Missing number & 0 & 0 & 0 \\
\hline & Number identification & 0 & 0 & 0 \\
\hline & Quantity discrimination & 0 & 0 & 0 \\
\hline & & $(0)$ & $(0)$ & $(0)$ \\
\hline
\end{tabular}

Coefficient correlation data indicate that the three assessments are positively correlated. The higher the students' performance on one assessment, the higher their scores are in another assessment. This is especially true between DIBELS-R and DIBELS-M, given the fact that both standardized achievement tests share common features and the $\mathrm{p}$ values are less than 0.05 .

\section{Discussions}

This study extends existing research in the following ways. First, the findings show that the students in the ABA classroom made more progress in the domain of cognitive skills than other skill domains. Cognitive skills serve as the foundation of many other skills and it is evidence that children's development of cognitive skills is vital to their later academic performance and socialization (Campbell et al., 2001). Thus, such skills are particularly emphasized in early childhood special education.

Second, the findings from ABLLS-R data reveal that the five students with autism were making progress and they all met their IEP goals at the end of the academic year across cognitive, social, academic, social, and motor skill domains. It is encouraging to see this data because even if these students' disabilities might slow down their learning process, each of them was learning and making progress toward their IEP goals. The practices that the therapists carried out in the ABA classroom included: (1) building new skills on students' prior knowledge, (2) breaking down the new skills into small steps, (3) providing explicit modeling of the skills, (4) planning opportunities for students to practice the skills, and (5) assessing skill mastery across settings and reteaching the skills if needed.

Third, although all of the students were making progress and met their IEP goals using ABLLS-R, none of them met their grade-level benchmarks when being tested through 
standardized achievement tests of DIBELS-R and DIBELS-M. To help students with autism meet their grade-level benchmarks, teachers in the ABA classroom should make a good connection between mastery learning assessments and standardized achievement tests. That is, they should intentionally and carefully design their teaching, which goes beyond discrete skills in mastery learning assessments. Perhaps, instead of starting from skill-specific assessments like ABLLS-R to determine the IEP goals for students with autism in the ABA classroom, the first step teachers should take is to look at global standardized achievement tests like DIBELS-R and DIBELS-M to get the big picture of their students' grade-level benchmarks. After knowing the benchmarks, teachers then begin to identify specific skills and tailor ABA therapy to help students meet grade-level benchmarks. An example of matching the skills in mastery learning assessments (i.e., ABLLS-R) and standardized achievement tests (i.e., DIBELS-R, and DIBELS-M) is shown in Table 7.

Table 7. Matching the skills across assessments

\begin{tabular}{|c|c|}
\hline $\begin{array}{l}\text { Step 1. Examining the grade-level benchmarks } \\
\text { in DIBELS-R and DIBELS-M }\end{array}$ & $\begin{array}{l}\text { Step 2. Identifying skill-focused tasks in ABLLS-R in } \\
\text { relation to the benchmarks }\end{array}$ \\
\hline$D I B E L S-R$ & ABLLS-R (Reading Skills) \\
\hline $\begin{array}{l}\text { Fluency assessment to measure their sound } \\
\text { fluency (FSF) }\end{array}$ & $\begin{array}{l}\text { Q1 Receptive letters } \\
\text { Q2 Labels letters }\end{array}$ \\
\hline Letter naming fluency (LNF) & $\begin{array}{l}\text { Q3 Receptive sounds of letter } \\
\text { Q4 Labels sounds of letters }\end{array}$ \\
\hline Phoneme segmentation fluency (PSF) & $\mathrm{N} / \mathrm{A}$ \\
\hline $\begin{array}{l}\text { Nonsense word fluency - correct letter sounds } \\
(\mathrm{NWF}-\mathrm{CLS})\end{array}$ & $\begin{array}{l}\text { Q7 Names letters in words reading left to right } \\
\text { Q9 Fill in missing letter of words }\end{array}$ \\
\hline $\begin{array}{l}\text { Nonsense word fluency - whole words read } \\
\text { completely and correctly (NWF - WRC) }\end{array}$ & $\begin{array}{l}\text { Q10 Read simple words } \\
\text { Q11 Decode words } \\
\text { Q12 Fills-in missing words }\end{array}$ \\
\hline$D I B E L S-M$ & ABLLS-R (Math Skills) \\
\hline Counting & $\begin{array}{l}\text { R1 Rote counts with prompts } \\
\text { R2 Rote counting } \\
\text { R3 Count objects with prompts } \\
\text { R4 Count give objects } \\
\text { R5 Count out objects from a larger set }\end{array}$ \\
\hline Missing number & $\begin{array}{l}\text { R6 Names numerals in sequence } \\
\text { R7 Names numbers } \\
\text { R20 Add numbers }\end{array}$ \\
\hline
\end{tabular}




\begin{tabular}{|c|c|}
\hline Number identification & $\begin{array}{l}\text { R8 Match number with same amount of objects } \\
\text { R21 Time telling } \\
\text { R22 Identify coins by name }\end{array}$ \\
\hline Quantity discrimination & $\begin{array}{l}\text { R9-R13 “more," "less," "some," "all," “zero/none” } \\
\text { R14 Add items to specified quantity } \\
\text { R15-R18 “same," "different," "greater," "add" } \\
\text { R23 Identify all coins by value } \\
\text { R24 Interchange coins to arrive at equal values } \\
\text { R25-R29 "equal," "unequal," "minus," "plus," } \\
\text { "subtract/take away" }\end{array}$ \\
\hline
\end{tabular}

Although there are many good programs and materials that are developed based on grade-level benchmarks, teachers still need to examine the skills across assessments closely. When teachers notice that some of the skills in the standardized achievement tests are not covered in the mastery learning assessments, they can develop their own materials or modify other skills tasks in ABLLS-R to teach students the skills. Taking an example from ABLLS-R, before presenting with the word "hat" and asking students to say "h," "a," "t," teachers can say the word "hat" without presenting the word and ask students to segment the sounds. In this way, students can develop phonemic awareness, a skill emphasized in DIBELS-R. Moreover, if conditions allow, teachers can add skills from ABLLS-R (or from other materials) to teach students the skills that might not be tested in standardized achievement tests, but equally important for them to master. With a good connection between the measures, it is likely to create greater opportunities for students to master skills and perform better on standardized achievement tests. By examining the performance of students with autism on ABLLS-R, DIBELS-R, and DIBELS-M, teachers can better understand "where" their students perform poorly on standardized achievement tests and "what specific skills" should be taught to help them succeed. Teachers need to be mindful of how to use mastery learning assessments to help students with autism perform better on standardized achievement tests, and not just meet IEP annual goals. Examining grade-level benchmarks and then identifying specific-focused tasks accordingly can help teachers maintain high expectations for their students and maximize the potential of ABA therapy to students with autism.

\section{Conclusion}

To prepare students with autism to meet their grade-level benchmarks, teachers must be given adequate professional development to think deeply about how to use standardized achievement tests and mastery learning assessments to inform their instruction, which should take into account the connection between individual skills and actual performance (Fuchs, Fuchs, \& Tindall, 1986) and the needs of students with disabilities (Nation, Clarke, Wright, \& Williams, 2006). Moreover, although helping students perform better on standardized achievement tests is important, education should not become a "teaching to the test" model. To create a more meaningful learning environment for students with autism, high-order 
thinking skills and fieldwork application experiences must be incorporated in the ABA classroom. Finally, because the selection of specific skill treatments in ABLLS-R is subjective, relying on teachers' experiences, conducting social validity to learn about the social significance of the target behavior, the appropriateness of the treatment procedures, and the social importance of the outcome (Cooper et al., 2007) is highly recommended. These preliminary findings of the present study provide researchers and teachers with useful information about how, when, and why students with autism demonstrate improved academic and behavioral performance through ABLLS-R and how teachers can improve ABA services to help students with autism succeed in standardized achievement tests.

\section{References}

Bloom, B. S. (1976). Human characteristics and school learning. New York: NY, McGraw-Hill.

Campbell, F. A., Pungello, E. P., Miller-Johnson, S., Burchinal, M., \& Ramey, C. T. (2001). The development of cognitive and academic abilities: Growth curves from an early childhood educational experiment. Developmental Psychology, 37(2), 231. http://dx.doi.org/10.1037/ 0012-1649.37.2.231

Centers for Decease Control and Prevention (CDCP). (2016). Autism spectrum disorder data and statistics. Retrieved from http://www.cdc.gov/ncbddd/autism/data.html

Cooper, J. O., Heron, T. E., \& Heward, W. L. (2007). Applied behavior analysis (2nd ed.). Upper. Saddle River, NJ: Pearson Merrill Prentice Hall.

DIBELS. (2016). Dynamic indicators of basic early literacy skills. Retrieved from https://dibels.org/dibels.html

DIBELS ${ }^{\circledR}$ Math. (2016). Overview. Retrieved from https://dibels.org/dibelsmath.html

Dunlap, G., Kern, L., \& Worcester, J. (2001). ABA and academic instruction. Focus on Autism and Other Developmental Disabilities, 16(2), 129-136. http://dx.doi.org/10.1177/108835760101600209

Fuchs, L. S., Fuchs, D., \& Tindall, G. (1986). Effects of mastery learning procedures on student achievement. Journal of Educational Research, 79(5), 286-291. http://dx.doi.org/10.1080/00220671.1986.10885693

Koegel, L. K., Koegel, R. L., \& Smith, A. (1997). Variables related to differences in standardized test outcomes for children with autism. Journal of Autism and Developmental Disorders, 27, 233-243. http://dx.doi.org/10.1023/A:1025894213424

Loiacono, V., \& Allen, B. (2008). Are special education teachers prepared to teach the increasing number of students diagnosed with autism? International Journal of Special Education, 23(2), 120-127.

Lovaas, O. I. (1987). Behavioral treatment and normal educational and intellectual functioning in young autistic children. Journal of Consulting and Clinical Psychology, 55, 
3-9. http://dx.doi.org/10.1037/0022-006X.55.1.3

Nation, K., Clarke, P., Wright, B., \& Williams, C. (2006). Patterns of reading ability in children with autism spectrum disorder. Journal of Autism and Developmental Disorders, 36(7), 911-919. http://dx.doi.org/10.1007/s10803-006-0130-1

Odom, S. L., Boyd, B. A., Hall, L. J., \& Hume, K. (2010). Evaluation of comprehensive treatment models for individuals with autism spectrum disorders. Journal of Autism and Developmental Disorders, 40, 425-436. http://dx.doi.org/10.1007/s10803-009-0825-1

Partington, J. W. (2016). The Assessment of Basic Language and Learning Skills - Revised (ABLLS-R). Retrieved from https://www.partingtonbehavioranalysts.com/page/ablls-r-25.html U.S. Department of Education, National Center for Education Statistics. (2016). Digest of Education Statistics, $2012 \quad$ (NCES 2014-015). Retrieved from https://nces.ed.gov/fastfacts/display.asp?id=64

\section{Copyright Disclaimer}

Copyright for this article is retained by the author(s), with first publication rights granted to the journal.

This is an open-access article distributed under the terms and conditions of the Creative Commons Attribution license (http://creativecommons.org/licenses/by/3.0/). 